Int. J. Electrochem. Sci., 12 (2017) 10239 - 10258

International Journal of

ELECTROCHEMICAL

SCIENCE

www.electrochemsci.org

\title{
A Facile Consistency Screening Approach to Select Cells with Better Performance Consistency for Commercial 18650 Lithium Ion Cells
}

\author{
Xiangming He ${ }^{1,2}$, Gan Zhang ${ }^{1}$, Xuning Feng ${ }^{1,2}$, Li Wang ${ }^{1, *}$, Guangyu Tian ${ }^{2}$, Minggao Ouyang $^{2}$ \\ ${ }^{1}$ Institute of Nuclear and New Energy Technology, Tsinghua University, Beijing 100084, P R China; \\ ${ }^{2}$ State Key Laboratory of Automotive Safety and Energy, Tsinghua University, Beijing 100084, P R \\ China \\ *E-mail: wang-1@tsinghua.edu.cn
}

doi: $10.20964 / 2017.11 .01$

Received: 6 June 2017 / Accepted: 29 August 2017 / Published: 12 October 2017

\begin{abstract}
A battery pack for electric vehicles always contains many individual cells, but even more must be used for those made of 18650 cells. Cell-to-cell inconsistency can undermine the performance of a battery pack, and requires investigation before its formation. Traditional consistency screening approaches may have to check the electrochemical performance of the individual cells one after another, requiring plenty of time to filter the massive cells, whereas this study proposes a more efficient screening approach to select cells with better electrochemical consistency. By the proposed approach, the cells are connected in series and cycled with the same current, which makes performance consistency screening more reliable and more efficient. The weight, size, sealing, and electrochemical performances were tested and analyzed. These basic comparative results allow researchers and engineers to obtain a facile understanding of the inconsistency present in 18650 cell products. The inconsistency of cells from five manufacturers is quantitatively compared. Traditional screening approaches are based on the cell traits listed above, whereas the proposed approach in this study takes reduced time in cell screening by connecting 120 selected cells in series and cycling them simultaneously. Pack tests were conducted to verify the proposed consistency screening approach. The battery pack formed by cells with poor consistency selected by the proposed screening approach has a lower initial capacity after pack formation and shows faster capacity decay after cycling than one formed by cells with better consistency selected by the proposed screening approach, indicating that the proposed facile screening approach is effective.
\end{abstract}

Keywords: lithium ion cell; consistency; screening approach; series; battery

FULL TEXT 
(C) 2017 The Authors. Published by ESG (www.electrochemsci.org). This article is an open access article distributed under the terms and conditions of the Creative Commons Attribution license (http://creativecommons.org/licenses/by/4.0/). 